\title{
Gastric Curvature Lymph Node
}

National Cancer Institute

\section{Source}

National Cancer Institute. Gastric Curvature Lymph Node. NCI Thesaurus. Code C154773.

A lymph node that is located between the two layers of the greater omentum, either superiorly along the cardiac half of the lesser curvature of the stomach or inferiorly along the pyloric half of the greater curvature of the stomach. 